\title{
Subsídios para o manejo de percevejos na fase inicial da cultura do milho
}

\author{
Taiane Lopes de Toledo', José Carlos Cazarotto Madalóz² e Leandro do Prado Ribeiro³
}

\begin{abstract}
Resumo - No sul do Brasil, os percevejos barriga-verde (Diceraeus furcatus e Diceraeus melacanthus) têm se constituído em pragas-chave do milho, causando expressiva redução na produtividade pelo ataque na fase inicial da cultura. Assim, neste informativo são apresentados aspectos aplicados relacionados à dinâmica de percevejos nos sistemas de produção milho-soja, características bioecológicas e comportamentais e as principais estratégias de monitoramento e manejo recomendadas para as condições de cultivo desse cereal na região.
\end{abstract}

Termos para indexação: Zea mays; Diceraeus furcatus; Diceraeus melacanthus; manejo integrado de pragas.

\section{Subsidies for stink bugs management in the initial phase of maize}

\begin{abstract}
In southern Brazil, the green belly stink bugs (Diceraeus furcatus and Diceraeus melacanthus) have been constituted in key pests of maize crops, causing significative reduction of crop productivity due to its damage in the initial phase. Thus, in this informative will be presented applied aspects related to insect pect dynamic in maize-soybean production systems, pest bioecologic and behavior characteristics as well as strategy of monitoring and management recommended for the growing conditions of these cereals in the region.
\end{abstract}

Index terms: Zea mays; Diceraeus furcatus; Diceraeus melacanthus; integrated pest management.

\section{A dinâmica do complexo de percevejos em sistemas de produção milho-soja}

Consideráveis avanços em produção e produtividade do milho foram observados nos últimos anos, em decorrência especialmente da expansão da adoção do sistema de plantio direto, do cultivo de híbridos de alta performance, além da ampla adoção do cultivo de milho geneticamente modificado $(B t)$ e do aumento da área cultivada em segunda safra ("safrinha"). No entanto, tais mudanças nos sistemas de produção e nas culturas em sucessão resultaram em alterações na dinâmica de percevejos, favorecendo sua multiplicação e sobrevivência, intensificando seus danos em hospedeiros anteriormente tidos como secundários, como o milho.

Em cultivos de primeira safra ("safra verão"), os danos observados em milho são decorrentes de indivíduos diapáusicos multiplicados no cultivo anterior, especialmente na soja (Figura 1). Após estabelecidas condições climáticas favoráveis (especialmente temperatura), os adultos diapáusicos restabelecem seu metabolismo e atacam o milho nas fases iniciais do desenvolvimento (Figura 1), pois é a primeira cultura implantada e disponível na paisagem. Após a alimentação no milho, tais indivíduos dispersam para cultivos de soja (hospedeiro preferencial), onde passam a se multiplicar (Figura 1). Em cultivos de segunda safra ("safrinha") implantados após cultivo de soja (sistemas sojamilho), as populações incidentes são maiores e oriundas de cultivos de soja recém-colhidos ou em fase de maturação fisiológica (estágio R6 em diante).

\section{Aspectos morfológicos e bioecológicos}

Embora outras espécies de percevejos, como o percevejo-marrom (Euschistus heros), possam incidir nas lavouras de milho, os percevejos barriga-verde Diceraeus furcatus e Diceraeus melacanthus (Figura 2B) são as espécies que causam os maiores prejuízos na fase inicial da cultura (GOMES et al., 2020). Tal fato decorre do hábito alimentar dessas espécies, que se alimentam preferencialmente no colmo (Figura 2F) e, consequentemente, atingem $\mathrm{o}$ ponto de crescimento (meristema apical) ou gemas laterais (futuras espigas). Além disso, apresentam ocorrência mais cedo (agosto/setembro) nos cultivos de milho de primeira safra, possivelmente por possuírem menores requerimentos de temperatura para restabelecimento do seu metabolismo em indivíduos diapáusicos em comparação a outras espécies (p. ex.: E. heros).

O percevejo $D$. furcatus apresenta em torno de $12 \mathrm{~mm}$ de comprimento, com o dorso pardo e a face inferior do corpo verde-clara (barriga-verde). $\mathrm{Na}$ face frontal da cabeça possui duas expansões pontiagudas (jugas) e um "espinho" da mesma cor do dorso em cada lado do tórax. Os ovos medem em torno de $0,8 \mathrm{~mm}$ de diâmetro, apresentando coloração verde-clara, dispostos comumente em duas filas paralelas, agrupados em 10 a 15 unidades. A incubação dos ovos ocorre em 6,4 dias, na temperatura de 25ㄷ (CHIARADIA, 2015). Quando ninfa, apresenta região inferior esverdeada e o dorso de coloração par-

Recebido em 3/4/2020. Aceito para publicação em 1/7/2020.

1 Eng.-agr., Universidade Federal da Fronteira Sul (UFFS), Chapecó, Santa Catarina. E-mail: tai.a@hotmail.com;

${ }^{2}$ Eng.-agr., M.Sc., Corteva Agriscience, São Miguel do Oeste, Santa Catarina. E-mail: jose.madaloz@corteva.com;

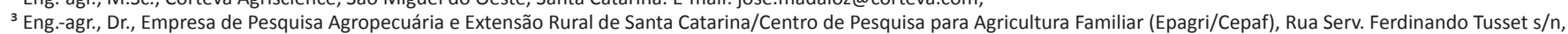

Bairro São Cristóvão, Chapecó, SC. E-mail: leandroribeiro@epagri.sc.gov.br, Fone: (49) 20497563. *Autor para correspondência. 


\section{Dinâmica de percevejos em sistemas milho-soja}

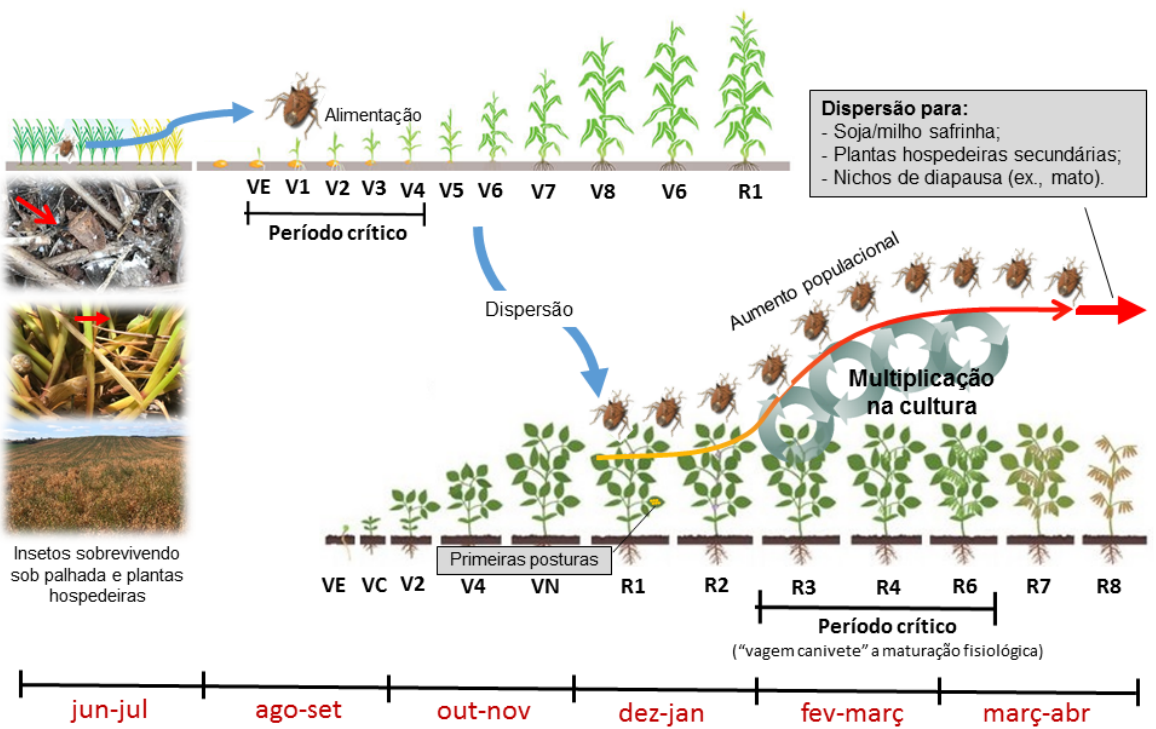

Figura 1. Dinâmica de percevejos em sistemas de produção milho-soja no sul do Brasil. Fonte: elaborado pelos autores

Figure 1. Dinamyc of stink bugs in maize-soybean production systems in southern Brazil Authors: from the authors

da, com máculas avermelhadas no abdome e três glândulas odoríferas alongadas de cor marrom-escura. A partir do quinto instar, apresenta dorso de cor esverdeada (CHIARADIA, 2015). As características morfológicas e bioecológicas do percevejo D. melacanthus (Figura 2B) são semelhantes ao $D$. furcatus.

Os percevejos barriga-verde possuem hábito alimentar polífago, incidindo principalmente em cultivo de gramíneas e leguminosas. $D$. furcatus é mais frequente em regiões de temperatura amena situadas no sul do Brasil (metade sul de Santa Catarina e Rio Grande do Sul). O percevejo D. melacanthus, por sua vez, ocorre geralmente em áreas de menores latitudes, como na metade norte de Santa Catarina e Paraná.

\section{Danos e período crítico de ocorrência}

Os percevejos causam danos nas plantas principalmente por se alimentarem de seiva no ponto de crescimento (meristema apical, Figura 2F) ao mesmo tempo que injetam substâncias com ação tóxica nos tecidos da planta (PANIZZI \& LUCINI, 2019). Como consequência, as plantas atacadas desenvolvem perfilhos anormais e folhas retorcidas (Figura 2E), com perfurações (Figura 2 $C, D)$. O desenvolvimento é lento e, além tas dominadas por outras plantas de milho e por plantas daninhas na lavoura (CHIARADIA, 2012). Tais efeitos são decorrentes de alterações hormonais e nas rotas de defesa das plantas, que conduzem a um menor desenvolvimento do sistema radicular e da planta como um todo. Em média, a incidência de um percevejo por metro de plantas ocasiona a redução de $11,5 \%$ na produtividade da cultura (CHIARADIA et al., 2016).

O período crítico em que o ataque dos percevejos causa danos consideráveis na cultura do milho compreende desde a emergência até o estádio V3/V4 (três a quatro folhas expandidas, Figura 1) e, quanto menor for a planta, maior a sensibilidade às toxinas injetadas pelo percevejo no momento da alimentação. Nas plantas com mais de cinco folhas expandidas ou com colmo medindo mais de $8-10 \mathrm{~mm}$ de diâmetro, o aparelho bucal dos percevejos não atinge o meristema apical. Por isso, a partir desse estádio o ataque desses insetos-praga não causa dano econômico. Quando se observa os sintomas do ataque do percevejo nas plantas, o dano já não pode



Figura 2. Percevejos barriga-verde (Diceraeus spp.) em cultivos de milho e soja no sul do Brasil: A) alimentação alternativa em plantas daninhas na entressafra; B) detalhes da morfologia de um adulto da espécie Diceraeus melacanthus; C, D, E) injúrias causadas em milho; F) detalhe da localização do percevejo barriga-verde no colmo do milho e sua posição corporal quando em alimentação e; F, G) adulto sobre vagem de soja e seus danos. Fotos: autores Figure 2. Green belly stink bugs (Diceraeus spp.) in corn and soybean crops in southern Brazil: A) alternative feeding on weeds in the off-season; $B$ ) details of the morphology of an adult of the species Diceraeus melacanthus; $C, D, E$ ) injuries caused in corn plants; F) details of the location of the green belly stink bug in the corn stalk and its body position when fed and; $F, G)$ adult on soybean pods and its damage. Photo: from the authors 
ser revertido ou mitigado (CHIARADIA, 2012).

Embora estudos apresentem valores divergentes quanto ao impacto de percevejos na fase inicial do milho (CHIARADIA et al., 2016; GOMES et al., 2020), o nível de dano econômico (NDE) atualmente preconizado para percevejos adultos de barriga-verde na fase inicial da cultura do milho situase sempre abaixo de 0,5 percevejo/m de plantas, considerando o impacto da praga na produtividade da cultura, os valores atuais do cereal no mercado e os custos de controle da praga. Todavia, há marcantes variações na suscetibilidade dos genótipos de milho disponíveis no mercado (CROSARIOL NETTO et al., 2015; CRUZ et al., 2016), especialmente quanto à expressão da resistência do tipo tolerância. Além disso, níveis diferenciados de adubação de cobertura podem, em hipótese, mitigar o impacto dos danos de percevejos na fase inicial da cultura, fato em investigação na Epagri/Cepaf.

\section{Estratégias de monitoramento}

A avaliação da infestação dos percevejos barriga-verde pode ser realizada de diferentes formas. A inspeção da base das plantas de milho (Figura 2F) pode ser feita na lavoura, preferencialmente nas horas mais quentes do dia, em dez pontos de amostragem representativos do talhão, logo após a emergência da cultura ("milho no palito").

O uso de atrativos como vagens verdes de feijão (Phaseolus vulgaris) ou grãos de soja imersos em água por 15 minutos, adicionando meia colher de sal de cozinha $(0,5 \%, p / v)$ depois de escorrer, são alternativas de monitoramento da população de percevejos em condições de pré-semeadura. Maços com 3 a 4 vagens de feijão ou $30 \mathrm{~g}$ de grãos de soja embebecidos em água + sal devem ser dispostos no solo de forma representativa em 10 pontos do talhão, preferencialmente ao final da tarde, realizando inspeção pela manhã (BIANCO, 2005). A presença de percevejos em até 2 armadilhas indica que a população é baixa, e o tratamento de sementes com inseticidas sistêmicos (neonicotinoides, especialmente) é suficiente para o manejo da praga.
Por sua vez, a presença de 3 a 5 armadilhas infestadas indica uma população média e risco moderado, sendo que o tratamento de sementes deve ser complementado com o monitoramento em pós-emergência e aplicação de inseticidas quando atingir o nível de controle. Mais que 5 armadilhas infestadas indica populações elevadas e probabilidade de risco de dano alto, havendo indicação de manejo na pré e pós-emergência do milho (BIANCO, 2005; BRUSTOLIN et al., 2011).

\section{Estratégias de manejo}

Por constituir em uma praga de sistemas, o adequado manejo em culturas antecessoras, como soja, cereais de inverno e plantas de cobertura ou infestantes (Figura 2A), reduz a população de percevejos nas áreas e o impacto na fase inicial do milho. Além disso, a adoção de boas práticas agrícolas, como a dessecação antecipada e o manejo de plantas voluntárias (CRUZ et al., 2016), são medidas de manejo cultural importantes.

O tratamento de sementes com inseticidas sistêmicos (neonicotinoides, especialmente) é imprescindível, mas garante apenas uma proteção parcial para a cultura em relação ao ataque de percevejos (CROSARIOL NETTO et al., 2015). Assim, em caso de elevada pressão populacional faz-se necessário a complementação com aplicações de inseticidas em pré e/ou pós-emergência. Pulverizações em pré-emergência podem apresentar eficácia reduzida pelo fato de os insetos estarem em nichos de diapausa ou escondidos no dossel da planta de cobertura, sendo recomendadas apenas em condições de elevada pressão populacional da praga, observadas através do monitoramento. Em condições de níveis de baixa a média infestação, pulverizações na pós-emergência associadas ao tratamento de sementes são as medidas mais recomendadas e alcançam níveis de controle satisfatórios pela interação aditiva ou sinérgica das duas estratégias (BRUSTOLIN et al., 2011). Todavia, o momento da pulverização em pós-emergência é importante para obtenção da melhor proteção, sendo recomendada aplicação entre 3 a 5 dias após a emergência ("milho no palito"). Todavia, inseticidas registrados deverão ser utilizados para tal finalidade (Tabela 1).

\section{Considerações finais}

Os danos de percevejos na cultura do milho têm sido crescentes nos últimos anos no sul do Brasil, necessitando atenção dos agricultores em relação aos potenciais impactos dessas espéciespraga na produtividade da cultura. Assim, o monitoramento das áreas de cultivo é essencial e, em caso de necessidade de adoção de medidas, o momento de aplicação e o reconhecimento do período crítico da cultura são aspectos fundamentais para uma melhor resposta do controle químico adotado. A adoção de boas práticas agrícolas, tais como o adequado manejo de cultivos antecessores e plantas de cobertura e o manejo de plantas daninhas resistentes (Figura $1 \mathrm{~A})$, são estratégias de manejo cultural importantes. O tratamento de sementes é essencial, porém, em elevada pressão populacional, há necessidade de complementação para proteção, com aplicações de inseticidas em pré e/ ou pós-emergência, dependendo do nível de infestação.

\section{Referências}

AGROFIT. Sistema de agrotóxicos fitossanitários. Brasília, DF, 2020. Disponível em: http://extranet.agricultura.gov.br/agrofit cons/principal_agrofit_cons. Acesso em: 06 julho 2020.

BIANCO, R. Manejo de pragas de milho em plantio direto. In: REUNIÃO ITINERANTE DE FITOSSANIDADE DO INSTITUTO BIOLÓGICO - GRÃOS, 11., 2005, Aguaí. Anais[...] Aguaí, 2005.

BRUSTOLIN, C.; BIANCO, R.; NEVES, P.M.O.J. Inseticidas em pré- e pós-emergência do miIho (Zea mays L.) associados ao tratamento de sementes sobre Dichelops melacanthus (Dallas) (Hemiptera: Pentatomidae). Revista Brasileira de Milho e Sorgo, Sete Lagoas, v.10, n.3, p.215-223, 2011. DOI: http:// dx.doi.org/10.18512/1980-6477/rbms. v10n3p215-223

CHIARADIA, L.A. Manejo integrado de pragas na cultura do milho. In: WORDELL FILHO, J.A.; CHIARADIA, L.A.; BALBINOT JUNIOR, A.A. (Orgs.), Manejo Fitossanitário da cultura do milho. Florianópolis: EPAGRI/DEMC, 2012. 156p. Florianópolis: Epagri, 2012. p. 231-237.

CHIARADIA, L.A. Biologia e descrição da fases de desenvolvimento de Dichelops furcatus. Agropecuária Catarinense, Florianó- 
Tabela 1. Inseticidas registrados para o manejo de percevejos barriga-verde (Diceraeus spp.) na pós-emergência da cultura do milho no Brasil (Agrofit, 2020)

Table 1. Registered insecticides to green belly stink bugs (Diceraeus spp.) management in the post emergence of maize in Brazil (Agrofit, 2020)



* Liberado com restrições de uso;

** Cadastro/renovação em andamento;

*** Consulta realizada nos sistemas de registro de cada estado em março de 2020.

1 Tipo de formulação (conforme ABNT NBR 12697/2004): EC = Concentrado emulsionável; SC = Suspensão concentrada; EW = Emulsão óleo em água; EG = Grânulos emulsionáveis; $\mathrm{SE}=$ Suspo-emulsão; WG = Granulado dispersível; $\mathrm{CS}=$ Suspensão de encapsulado; $\mathrm{SG}$ = Granulado solúvel; $\mathrm{SP}=$ Pó solúvel

polis, v.27, p.83-88, 2015. Disponível em: http://publicacoes.epagri.sc.gov.br/index. php/RAC/article/viewFile/565/469

CHIARADIA, L.A.; NESI, C.N.; RIBEIRO, L.P. Nível de dano econômico do percevejo barriga verde, Dichelops furcatus (Fabr.) (Hemiptera: Pentatomidae), em milho. Agropecuária Catarinense, Florianópolis, v.29, p.63-67, 2016. Disponível em: http://publicacoes.epagri. sc.gov.br/index.php/RAC/article/view/93

CROSARIOL NETTO, J.; MICHELOTTO, M.D.; GRIGOLLI, J.F.J.; GALLI, J.A.; PIROTTA, M.Z.; BUSOLI, A.C. Damages caused by Dichelops melacanthus (Heteroptera: Pentatomidae) in conventional and transgenic corn hybrids. Bioscience Journal, Uberlândia, v.31, p.1092-1101, 2015. DOI: https://doi. org/10.14393/BJ-v31n4a2015-26323

CRUZ, I.; BIANCO, R.; REDOAN, A.C.M. Potential risk of losses in maize caused by Dichelops melacanthus (Dallas) (Hemiptera: Pentatomidae) in Brazil. Revista Brasileira de Milho e Sorgo, Sete Lagoas, v.15, n.3., p.386-397, 2016. DOI:https://doi.org/10.18512/19806477/rbms.v15n3p386-397
GOMES, E.C.; HAYASHIDA, R.; BUENO, A.F. Dichelops melacanthus and Euschistus heros injury on maize: basis for re-evaluating stink bug thresholds for IPM decisions. Crop Protection, Guildford, v.130, e105050, 2020. DOI: https://doi.org/10.1016/j. cropro.2019.105050

PANIZZI, A.R.; LUCINI, T. Body position of the stink bug Dichelops melacanthus (Dallas) during feeding from stems of maize seedlings. Brazilian Journal of Biology, São Carlos, v.79, p.304-310, 2019. DOI: http:// dx.doi.org/10.1590/1519-6984.18250 